Int. J. Dev. Biol. 51: 389-395 (2007)

doi: $10.1387 / \mathrm{ijdb} .0622531 \mathrm{w}$

Original Article

\title{
Soluble membrane-type 3 matrix metalloproteinase causes changes in gene expression and increased gelatinase activity during Xenopus laevis development
}

\author{
LOGAN A. WALSH, COLIN A. COOPER and SASHKO DAMJANOVSKI* \\ Department of Biology, University of Western Ontario, London, ON, Canada
}

\begin{abstract}
Matrix metalloproteinases (MMPs) are a family of endopeptidases that cleave and remodel the extracellular matrix (ECM). Membrane-type 3 MMP (MT3-MMP) is a membraneanchored MMP, which has recently been shown to 'shed' from the cell surface in a soluble form upon proteolytic cleavage. Shed MT-MMPs can activate gelatinase-A in vitro and have been directly linked to the metastatic potential of many cancers. Here we examined the effect of ectopic expression of full-length tethered and shed (soluble) forms of MT3-MMP during Xenopus laevis development. Injection of mRNA coding for full-length tethered MT3-MMP resulted in the delayed onset of gastrulation and subsequent defects. Phenotype severity and the frequency of embryo death were dose-dependent. Dose-dependent defects were also observed with the injection of mRNA of the soluble form, but the phenotypes and frequencies of death were greater. Histological analysis of injected embryos demonstrated defects in the organization of axial structures, such as the neural tube and somites. Embryos injected with full-length MT3-MMP mRNA showed no significant changes in expression levels of the tissue specific genes endodermin, chordin and muscle actin when examined by semi-quantitative RT-PCR. In contrast, embryos injected with the soluble form of MT3-MMP exhibited decreased expression of these same marker genes. In addition, while full-length tethered MT3-MMP failed to alter gelatinase activity, a $50 \%$ increase was measured in response to injection of the soluble form, suggesting that the two forms of this protein could play distinct roles during embryogenesis.
\end{abstract}

KEY WORDS: matrix metalloproteinase, Xenopus laevis, MT3-MMP

\section{Introduction}

Extracellular matrix proteins facilitate the cellular movements and novel cell-cell interactions that occur during development. Due to their ability to cleave extracellular matrix (ECM) and other membrane linked proteins, matrix metalloproteinases (MMPs) play critical roles in many developmental processes (VanSaun and Matrisian, 2006), (Stamenkovic, 2003; Damjanovski et al., 2001). MMPs are a diverse family of $24 \mathrm{Zn}^{2+}$ dependent endopeptidases that are secreted predominantly as inactive zymogens (pro-MMPs) (Freije et al., 2003) Although most secreted MMPs are activated in the extracellular milieu by other proteases, membrane-type MMPs (MT-MMPs) contain a furin recognition amino acid sequence that allows intracellular activation prior to secretion (Kang et al., 2002). Once active, an MMP can degrade a variety of substrates, some of which are targets of multiple MMPs (Hernandez-Barrantes et al., 2002). Consequently, sev- eral MMPs may act in concert to dramatically alter the composition of the ECM and thus alter cell signaling interactions and movements that are needed for proper early development (Montero and Heisenberg, 2004), (Somiari et al., 2006) and (Pickard and Damjanovski, 2004). In the current study, we focus on the role of Xenopus laevisMT3-MMP, a newly described member of the MTMMP family of proteins.

Despite the potent effects of MMPs on ECM remodeling, targeted-inactivation of most MMPs in mice surprisingly produces viable offspring, with the exception of the MT1-MMP null mouse, which is non-viable (Somerville et al., 2003) and (Holmbeck et al., 1999). The severity of the MT1-MMP-/- phenotype may be in part ascribed to the loss of MT1-MMP's unique and dynamic functions,

Abbreviations used in this paper: ECM, extracellular matrix; GFP, green fluorescent protein; MMP, matrix metalloproteinase; MT3, membranetype 3 .

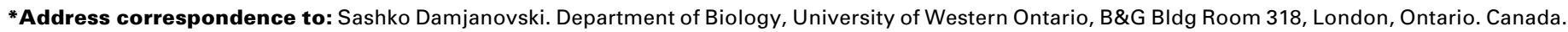
N6A 5B7. Tel: +1-519-661-2111 (x84704). Fax: +1-519-661-3935. e-mail: sdamjano@uwo.ca Web: http://publish.uwo.ca/ sdamjano/
} 
particularly its capacity to undergo ectodomain shedding and activate pro-MMP2 (Osenkowski et al., 2004). As MT-MMPs are secreted as active molecules at the plasma membrane and then are shed in a soluble form, they gain access to a larger variety of substrates. MT-MMPs role in pro-MMP activation (Wang et al., 2004a) is of particular developmental interest as many recent studies have focused on the activation of gelatinases MMP-2 and MMP-9, as these powerful enzymes are associated with a number of pathological conditions and important developmental events (Coussens et al., 2000) (Wiseman et al., 2003) and (Hoikkala et al., 2006). Understanding whether an MT-MMPs is shed or not and whether it activates important pro-MMPs would greatly enhance our understanding of their developmental roles.

Membrane-type 3 MMP (MT3-MMP, Figure 1) is highly homologous to MT1-MMP in both structure and function; it is present in the membrane in an active form, it can also undergo ectodomain shedding and activates MMP-2 (Zhao et al., 2004). We have previously cloned the $X$. laevis ortholog of MT3-MMP and described its expression during early development (Hammoud et al., 2006). MT3-MMP is not significantly expressed during early $X$. laevis development until late tailbud stages where it is primarily expressed in anterior and neural structures. Injection of mRNA encoding the full-length protein into fertilized eggs, resulted in MT3-MMP ectopic expression, leading to embryonic death within 48 hours (Hammoud et al., 2006).

In this study, we show that injection of mRNA coding for fulllength tethered MT3-MMP into early $X$. laevis embryos results in gastrulation defects and improper development of axial structures. Of note, ectopic expression of full-length protein did not affect normal expression of tissue-specific genes, nor did it alter gelatinase activity. In contrast, injection of mRNA coding for the soluble form of MT3-MMP increased gelatinase activity and altered the expression of most tissue-specific genes tested. Therefore, although the effects of mRNA injection of MT3-MMP (the full-length tethered form) are significant, injection of mRNA coding for soluble MT3-MMP has even broader and more profound effects on development.

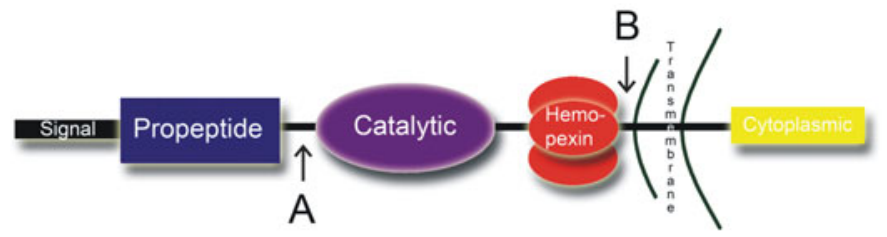

5

Full-length mRNA construct

$3^{\prime}$

5' Soluble mRNA construct $\quad 3$ '

Fig. 1. Schematic representation of the major protein domains of MT3-MMP. Signal sequence: targets MT3-MMPfor secretion. Propeptide domain: interacts with the catalytic domain and inhibits the active site where proteolysis occurs. Catalytic domain, zinc binding domain and active site for proteolysis. Hemopexin domain, binding site for substrates and inhibitors. Transmembrane domain, tethers MT3-MMP to the cell membrane. Cytoplasmic domain, function is largely unknown, but implicated in intracellular trafficking, surface distribution and signal transduction. (A) Furin cleavage site for proteolytic activation. (B) Site cleaved for ectodomain shedding.

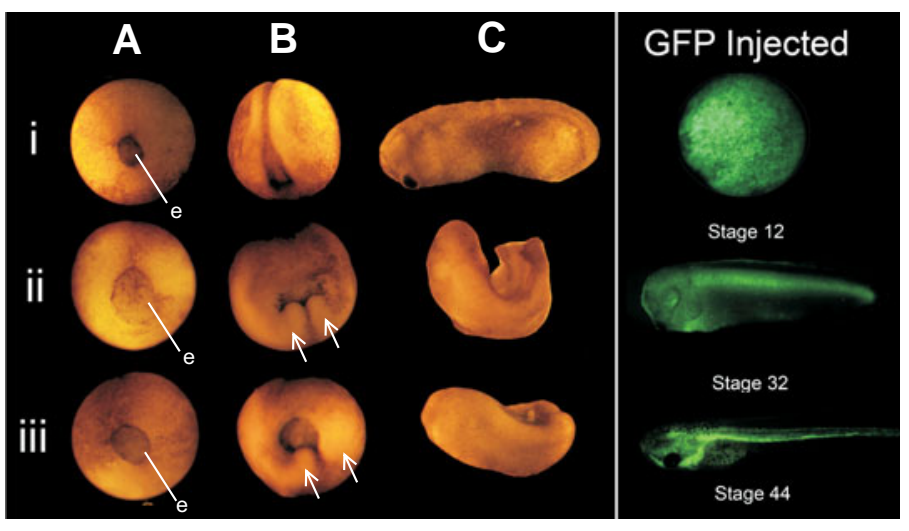

Fig. 2. Phenotypic consequences of MT3-MMP mRNA injections. Injection of $500 \mathrm{pg}$ of full-length (ii) or soluble (iii) MT3-MMP mRNA into stage $1 \mathrm{X}$. laevis embryos results in failed blastopore closure (' $\mathrm{e}$ ' represents visible endoderm), endoderm protrusion (arrows), axis perturbation, delayed onset of gastrulation and death as compared to uninjected controls (i). (A,B,C) Represent stages 12, 18 and 28 respectively. At stage 28, injected embryos display neural and head structure abnormalities, as well as truncated axes. Observed phenotypes and developmental delays were dose-dependent. Right panel. X. laevis embryos injected with 1 ng of GFP mRNA show no phenotypic effects.

\section{Results}

\section{Injection of MT3-MMP mRNA perturbs development}

Injection of either MT3-MMP mRNA construct into fertilized embryos delayed the onset of gastrulation and produced developmental defects that ranged from improper blastopore closure to endoderm protrusions with resultant axial and neural tube closure defects (Figure 2). Over 95\% of embryos injected with either construct died within 5 days of fertilization (data not shown). Injection of GFP mRNA (at the same doses as MT3-MMP mRNA injections) and the subsequent expression of GFP protein were not associated with increased embryonic death and did not perturb embryogenesis even at the highest injection doses (Figure 2).

At stage 12, when control and GFP-injected embryos were completing gastrulation (Figure 2Ai and data not shown), embryos injected with 500pg of mRNA of either soluble or tethered MT3-MMP resulted in embryos with large visible areas of endoderm (Figure 2Aii, iii).

Similarly at stage 18, (Figure 2Bi), embryos injected with either the full-length or soluble MT3-MMP construct displayed improper neural tube closure phenotypes that were exemplified by two visible ectodermal protrusions underlying a still open blastopore (arrows Figure 2Bii, iii).

Injected embryos with gastrulation and neurulation defects further continued to develop with phenotypes that ranged from minor axis perturbation and kinks, to the severe lack of axial structures. At stage 28 (Figure 2Ci), injected embryos displayed kinked axes and forked tails (Figure 2Cii, iii). Common phenotypes were observed during theses stages in embryos injected with either the full-length tethered or soluble construct of MT3MMP (compare Figure 2Cii and 2Ciii), though soluble form mRNA injections had more extreme defects (data not shown). The frequency of death was dose-dependent, regardless of the isoforms 


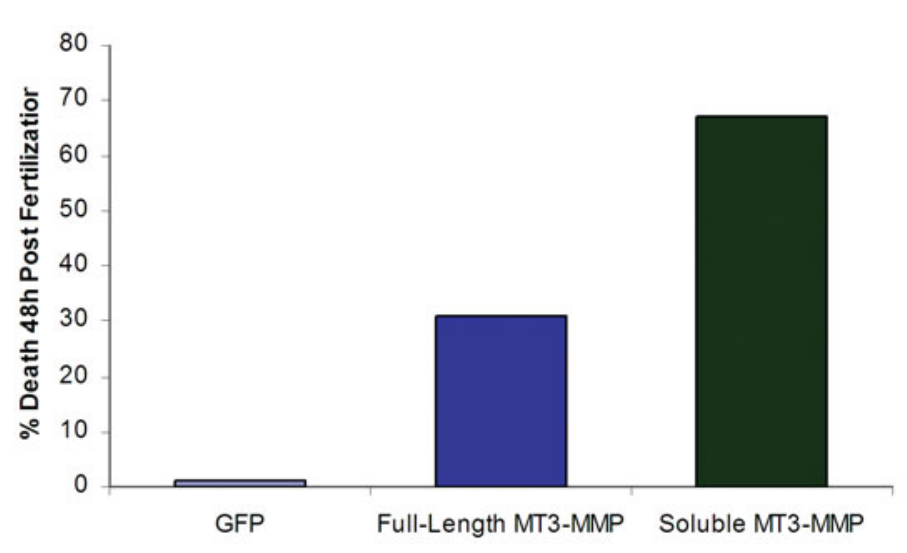

Fig. 3. mRNA injection coding for soluble MT3-MMP causes increased frequency of death. Five hundred picograms of GFP injected into stage $1 \mathrm{X}$. laevis embryos had no effect on death. Full-length MT3MMP mRNA injections resulted in a 31\% increase in death at the same dose, while soluble MT3-MMP resulted in a 67\% increase. Data is from one representative experiment repeated 3 times with consistent results.

injected (data not shown), however, there was overall more death with soluble MT3-MMP than with full-length MT3-MMP (Figure 3).

\section{Histological analysis reveals major anatomical structures in all injected embryos}

MT3-MMP mRNA injection was associated with significant embryonic death and axial defects in surviving embryos. To investigate the phenotypes seen in surviving embryos at the tissue level, they were fixed, sectioned and histologically stained. Readily identifiable major tissues and organs, including the cement gland, eye, otic vesicle, neural tube, notochord, somites and branchial arches were examined. Surprisingly, excluding the axial defects, the major organs and tissues were grossly indistinguishable between control and MT3-MMP injected embryos (Figure 4 and data not shown). Despite the gross appearance of the major structures, further investigation revealed severe anomalies within these major organs, including misaligned somites and defects in formation of the neural tube (Figure $4 \mathrm{Bi}$, ii, $4 \mathrm{Ci}$, ii). These defects may have contributed to the axis defects produced by the MT3MMP mRNA injections.

\section{Semi-quantitative RT-PCR analysis of tissue-specific marker genes revealed changes in expression after injection of mRNA coding for soluble MT3-MMP}

As ECM remodeling is known to influence cell signaling and therefore lead to changes in gene expression, specific genes were used to assay endoderm, notochord, muscle and neural development (endodermin, chordin, muscle actin and sox2, respectively). Semi-quantitative RT-PCR was used to assess the effects of MT3-MMP mRNA injections on changes in expression levels of these marker genes. There was no significant change in marker gene expression in embryos injected with full-length MT3MMP mRNA (Figure 5). Accordingly, despite the gross anatomical defects seen with the full-length MT3-MMP mRNA injections, gene expression in these embryos is largely unaltered. However, embryos injected with mRNA for the soluble form of MT3-MMP showed decreased marker gene expression. The most striking decreases in marker gene expression were found in the notochord and muscle (Figure 5), where chordin and muscle actin levels were less than $40 \%$ of the controls. In addition endodermin decreased dramatically in embryos injected with mRNA coding for soluble MT3-MMP. There was no dramatic decrease in the neural tissue marker gene (soxz) in injected embryos. Injection of GFP mRNA did not affect marker gene expression (data not shown). Thus, while both full-length and soluble mRNA construct injections resulted in gross developmental defects, only the injection of mRNA coding for the soluble form altered the levels of important developmental genes.

\section{Gelatinase assay}

MMP-2 and MMP-9 (gelatinase A and B respectively) are potent enzymes that can greatly impact many cellular events. Of importance is the finding that MT3-MMP is known to activate proMMP2 (Sounni and Noel, 2005). While both full-length and shed MT3-MMP can degrade gelatin (Somerville et al., 2003) (Shimada et al., 1999) and (Kang et al., 2000) of greater importance to cellular function and therefore development, is its ability to activate pro-MMP2 (Kang et al., 2000). As increased MMP-2 activity could in part account for the severe phenotype seen with MT3MMP mRNA injections, a quantitative gelatinase activity assay

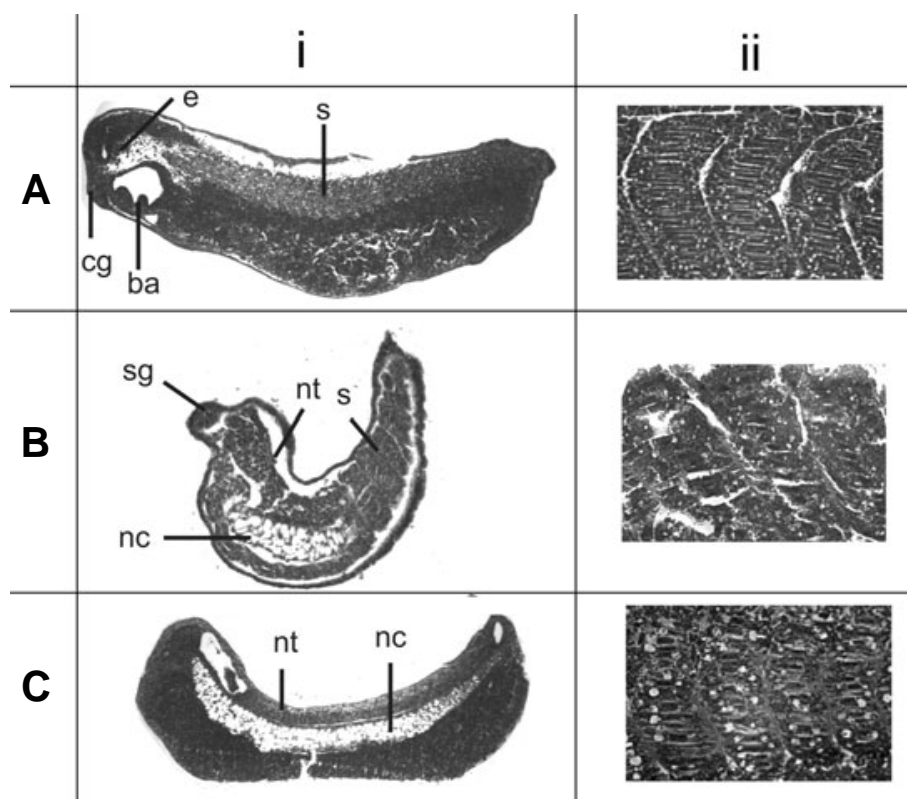

Fig. 4. Histological analysis of major tissues following MT3-MMP mRNA injections. Histological sections of stage $35 \mathrm{X}$. laevis embryos highlighting defects after injection of MT3-MMP mRNA into stage 1 embryos. (Ai) Uninjected control, (Bi) injected with full-length MT3-MMP and $\mathbf{( C i ) ~ i n j e c t e d ~ w i t h ~ s o l u b l e ~ M T 3 - M M P . ~ T h o u g h ~ n o t ~ a l l ~ t i s s u e s ~ a r e ~}$ visible in all sections, major anatomical structures were present in all injected and control embryos including; ba-branchial arches, cg-cement gland, e-eye, nc-notochord, nt-neural tube, s-somites. Though present, structures were often malformed. Column (ii) represent higher magnifications of the somites of the embryos seen in column (i) (or a serial section). Control somites (Aii) are well organized into a distinct chevron shape, while somites following full-length (Bii) or soluble (Cii) MT3-MMP mRNA injections were poorly organized. Embryos were paraffin embedded, sectioned at $6 \mu \mathrm{m}$ and stained with hematoxylin and eosin. 

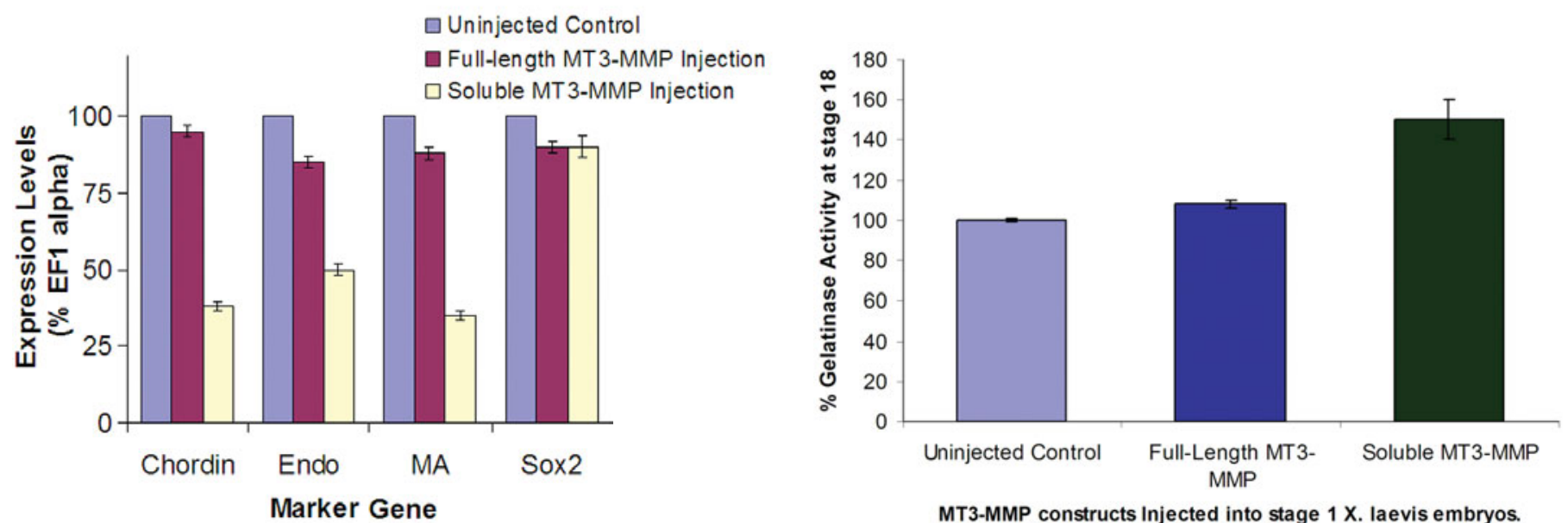

Fig. 5 (Left). mRNA coding for soluble, but not full-length MT3-MMP affects tissue specific marker gene expression. Injection of 500 pg of fulllength MT3-MMP mRNA into one cell embryos did not alter levels of marker genes when assayed at 24 h after injection. Injection of 500 pg of soluble MT3-MMP mRNA into one cell embryos decreased levels of chordin, endo and MA mRNA as compared to uninjected embryos. Sox2 levels did not change following injection of either mRNA construct. Levels in control (uninjected) embryos were set as $100 \%$. Expression levels were measured as compared to levels of EF1 $\alpha$ mRNA. The figure represents an average of 3 repeats. Standard error bars are shown.

Fig. 6 (Right). Injection of soluble MT3-MMP mRNA causes increased gelatinase activity. Injection of 500 pg of full-length MT3-MMP mRNA into one-cell embryos did not alter gelatinase activity when tested 18 hours after injection. Injection of 500 pg of soluble MT3-MMP mRNA into one-cell embryos increased gelatinase activity by $50 \%$ as compared to uninjected embryos. The figure represents an average of 3 repeats. Standard error bars are shown.

was performed to confirm and quantify any changes in gelatinase activity in MT3-MMP injected embryos. Embryos injected with $500 \mathrm{pg}$ of full-length MT3-MMP mRNA showed no significant increase in gelatinase activity at stage 12 (Figure 6). In contrast, injection of 500pg mRNA coding for soluble MT3-MMP, resulted in a $50 \%$ increase in gelatinase activity as compared to uninjected controls (Figure 6). While the assay does not resolve whether MMP-2 or MMP-9 activity is increased, the fact that only MMP-2 is activated by MT3-MMP is of note. Semiquantitative RT-PCR using MMP-2 specific primers showed no change in MMP-2 mRNA expression for any of the injections (data not shown). Therefore, the effects are limited to potential increased activation of existing MMP-2 protein and not to the increased expression of its message. The activation of MMP-2 following soluble MT3-MMP mRNA injections also correlate with the changes in maker gene expression seen following injection of the same mRNA.

\section{Discussion}

Ectopic expression of full-length and soluble MT3-MMP results in gastrulation defects and death

MT3-MMP is a member of the MT-MMP family that is homologous to MT1-MMP, the loss of which in mice is embryonic lethal (Holmbeck et al., 1999). We have previously cloned the $X$. laevis ortholog of MT3-MMP and shown that it is expressed late in development and restricted to anterior and neural structures (Hammoud et al., 2006). In this current study, we have demonstrated that ectopic expression of a full-length tethered, or an equal amount of a soluble form of MT3-MMP results in a range of phenotypes from minor axis perturbation to death. An important consideration to note here is MT3-MMP's expression pattern during normal development. As MT3-MMP mRNA is not present at significant levels until well after gastrulation, it is presumably not required prior to gastrulation (Hammoud et al., 2006). Data presented here however, describes that when MT3-MMP is ectopically expressed, gastrulation and development are perturbed, suggesting that MT3-MMP substrates are present in the developing embryo prior to MT3-MMP expression. Since MT3-MMP and most other MMPs have potent effects when they are activated, their expression during development must be well regulated temporally and spatially. Interestingly, in the embryos that survived gastrulation, most of the defects at later stages of development (stage 30) are found in axial and neural structures where endogenous MT3-MMP is found. As late developmental defects are restricted to locations where native MT3-MMP signaling pathways are present, there may be other proteins interacting with MT3-MMP to regulate not only its temporal, but also its spatial expression and activity.

\section{Increased phenotype severity and frequency of death upon injection of soluble MT3-MMP mRNA}

We hypothesize that both native MT3-MMP and the injected tethered and soluble isoforms, are all capable of performing similar functions during remodeling events. The unique actions produced by ectopic expression of equal amounts of soluble, but not full-length MT3-MMP may be attributed to: 1) a mechanism that regulates surface distribution and function that is dependent on the cytoplasmic tail, or 2) the lack of a mechanism to shed the full-length protein early in development. Both injected forms likely cleave a variety of substrates and alter cellECM interactions, cytokine release from the ECM and cell survival. Being shed into the extracellular environment however, should or may permit the soluble form to interact with 
more substrates increasing its impact on ECM remodeling. As such, we contend that the severity of the phenotype and frequency of death associated with injection of mRNA coding for a soluble form of MT3-MMP is due to the difference in spatial distribution of these two forms (Shimada et al., 1999). In addition, the cytoplasmic domain found on the C-terminus of the full-length MT3-MMP is implicated in cell surface distribution and turnover (Cao et al., 2004). This adds another level of regulation and surface distribution to the full-length form that would not be found upon mRNA injection coding for the soluble form. We suggest that unlike the full-length form, soluble MT3MMP has free, unregulated access to the pericellular environment, which results in a wider impact on ECM remodeling and by inference, the severity of the phenotype.

\section{Ectopic expression of soluble MT3-MMP alters gene ex- pression}

Ectopic full-length MT3-MMP had little impact on the expression of a number of tissue-specific marker genes. Consistent with the hypothesis that the soluble form has broader spatial distribution and access to substrates and is therefore more toxic, injection of soluble MT3-MMP mRNA also altered marker gene expression. Ectopic soluble MT3-MMP resulted in lower expression of chordin, endodermin and muscle actin, but did not change sox2 expression. The miss-regulation of these genes is potentially a downstream result of the inappropriate activation of MMP-2 during development by the injected soluble form of MT3-MMP. Their miss-regulation also may result in the increased phenotypic severity and frequency of death that is seen with the soluble isoform mRNA injections.

\section{Effect of MT3-MMP expression on gelatinase activity}

Injection of full-length or soluble MT3-MMP form mRNA at equal doses resulted in significant embryonic death within 2 days with the frequency being significantly higher with the latter. In surviving embryos, similar phenotypes (short, kinked axis and neural defects) were induced by both protein isoforms. Of note, only embryos injected with the soluble form displayed changes in gelatinase activation. This again supports the idea that the activity of the tethered form is restricted, perhaps spatially, while the soluble or shed form has greater access to substrates.

Although MT1-MMP and MT3-MMP activate MMP-2, colocalize and share delivery mechanisms, they act independently and almost never in concert (Wang et al., 2004b). Recent evidence suggests that a mechanism at the cell surface where MT1-MMP and MT3-MMP serve to negatively regulate each other (Jiang and Pei, 2003). We propose that the activation of pro-MMP-2 during early development, which is normally accomplished by the activity of MT1-MMP, is being inhibited upon the injection of full-length MT3-MMP mRNA. Conversely, the soluble form of MT3-MMP, which does not co-localize with MT1-MMP, likely does not interact in a regulatory feedback loop and as a result, there is increased pro-MMP-2 activation after mRNA injection of the soluble, but not the full-length, MT3-MMP construct. Further, the cell surface activation of MMP-2 by MTMMPs makes use of tissue inhibitors of metalloproteinases (TIMPs) (Zhao et al., 2004). Accordingly a shed or soluble MTMMP would be unrestricted to cell surface interactions with
TIMPs and could activate pro-MMP-2 away from the cell surface independently of TIMP.

\section{Conclusions}

Ectodomain shedding by MT-MMPs may ascribe additional functions to MT-MMPs that other secreted MMPs lack. Here we demonstrate that the delicate balance between tethered and shed forms of MT-MMPs can have diverse and profound effects on ECM remodeling and the cellular events associated with it. Furthermore, for the first time we show that the shed form of any MT-MMP can activate MMP-2 in vivo. Due to the spatial and temporal differences in the tethered and shed forms, they likely manifest their activity in very different ways, particularly with regards to subsequent changes in gene regulation. Taken together, these results emphasize the importance of elucidating the regulatory mechanisms that control the activity and shedding of MT-MMPs.

\section{Materials and Methods}

\section{Embryo rearing and fertilization}

Xenopus laevis were reared and fertilizations performed according to standard procedure (Wu and Gerhart, 1991) and protocols approved by University of Western Ontario Animal Care and Veterinary Services. Embryos were staged according to Nieuwkoop and Faber (1956).

\section{mRNA synthesis and injections}

The full-length $X$. laevis MT3-MMP cDNA and a truncated (soluble) form were subcloned into the T7TS plasmid such that sequence of interest was flanked by 5' and 3' UTR of the $X$. laevis $\beta$-globin gene (a gift of PA Krieg). The cDNA of the truncated form was generated by PCR based on know sequences (Hammoud et al., 2006). The truncated form corresponds to amino acids 1-539. This truncation was selected at amino acid 539 to obtain a resultant cDNA coding for the signal, propeptide, catalytic and hemopexin domains inclusively (Fig. 1). Following mRNA injection, translation and processing of this protein in the endoplasmic reticulum and Golgi would result in the intracellular cleavage of the signal sequence and prodomain, producing a soluble form of MT3-MMP containing only catalytic and hemopexin domains (48 kDa from tyr124asp539), (Hammoud et al., 2006). Capped polyadenylated RNA of both the full-length and soluble forms was synthesized (mMachine, Ambion, Austin, TX) and transcribed message integrity and concentration were determined using gel electrophoresis and spectrophotometery. De-jellied fertilized embryos were injected at the 1-cell stage with increasing amounts of RNA (250, 500 or 1000pg). Unfertilized, lysed and other dead embryos were removed within the first 3 hours as this time point was prior to the time when an effect of the injected message would be observed. At least 75 embryos were injected with each dose and injections were repeated three times.

\section{RNA extraction and semi-quantitative RT-PCR}

Total RNA (RNA-EASY KIT, Qiagen, Mississauga, On) was isolated from stage 18 uninjected embryos and stage 18 embryos injected at the 1-cell stage with MT3-MMP mRNA constructs. After confirmation of RNA quality and quantity by gel electrophoresis, complementary DNA was generated (SuperScript II Reverse Transcriptase, Invitrogen, Burlington, $\mathrm{ON})$.

Primers were chosen to assay for a number of tissue specific marker genes. (chordin-notochord, endodermin-endoderm, muscle actin-muscle, sox2-pan neural, EF1 $\alpha$-internal control)

Chordin 5'-cctccaatccaagactccagcag-3,

5'-ggaggaggaggagctttgggacaag-3' (Sasai etal., 1994) 


\section{Endodermin}

Muscle Actin

5'-agcagaaaatggcaaacacac-3',

5'-ggtcttttaatggcagcaacaggt-3' (Sasai et al., 1996)

5'-gctgacagaatgcagaag-3',

5'-ttgcttggaggagtgtgt-3' (Klein et al., 2002)

Sox2 5'-gaggatggacacttatgcccac-3',

5'-ggacatgctgtaggtaggcga-3' (De Robertis et al., 1997)

EF1 $\quad$ 5'-tgttggcagagtggagactg-3',

5'-ggccaagtggaggatagtca-3' (Dje et al., 1990)

Thirty cycles and an annealing temperature of $55^{\circ} \mathrm{C}$ were used for all PCRs. Several reactions were run to ensure that 30 cycles were within the exponential amplification phase. The products were resolved on a $0.8 \%$ agarose gel, ethidium bromide stained and photographed using the BioRad Gel Doc 1000 system (Bio-Rad Laboratories, Hercules, CA). BioRad Quantity One 4.4.0 software was used to quantify the intensity of the PCR product bands. For quantification, relative expression was measured as compared to expression of EF1 $\alpha$ using a Bio-Rad Gel Doc 1000 system and Quantity One imaging software (Bio-Rad laboratories). Experiments were repeated three times.

\section{Histology}

$X$. laevis embryos were paraffin-embedded and sectioned at $5 \mu \mathrm{m}$. Sections were subsequently stained with hematoxylin and eosin (Molecular Pathology, Robarts Research Institute, University of Western Ontario).

\section{Gelatinase activity assay}

At stage 12, ten control embryos and those injected with either fulllength or soluble MT3-MMP were assayed for changes in gelatinase activity in a 96 well plate using fluorescence labeled gelatin (Gelatinase assay kit, Molecular Probes, Portland, OR). Briefly, one embryo was placed in each well with $200 \mu$ l reaction buffer and lysed with vigorous up and down pippetting. Ten micrograms of $D Q$ gelatin was then added and samples incubated for 30 mins at room temperature. Fluorescence was measured using a Tecan Safire ${ }^{\mathrm{TM}}$ Multi Detection Fluorescence Reader.

\section{Photography}

Digital images of embryos were captured with a Leica Fluo ${ }^{T M}$ MZ FCIII dissecting scope and a Photometrics Cool SNAPTM CF camera and processes with Adobe Photoshop CS and Corel Draw 12.

\section{Acknowledgements}

We are very grateful to Dr. Kim Roberts and Dr. S.J. D'Souza for their critical evaluation of this manuscript. This research was supported by an NSERC Discovery Grant to S.D.

\section{References}

CAO, J., KOZAREKAR, P., PAVLAKI, M., CHIARELLI, C., BAHOU, W.F. and ZUCKER, S. (2004). Distinct roles for the catalytic and hemopexin domains of membrane type 1-matrix metalloproteinase in substrate degradation and cell migration. J Biol Chem 279: 14129-39.

COUSSENS, L.M., TINKLE, C.L., HANAHAN, D. and WERB, Z. (2000). Mmp-9 supplied by bone marrow-derived cells contributes to skin carcinogenesis. Cell 103: 481-90.

DAMJANOVSKI, S., AMANO, T., LI, Q., PEI, D. and SHI, Y.B. (2001). Overexpression of matrix metalloproteinases leads to lethality in transgenic Xenopus laevis: Implications for tissue-dependent functions of matrix metalloproteinases during late embryonic development. Dev Dyn 221: 37-47.

DE ROBERTIS, E.M., KIM, S., LEYNS, L., PICCOLO, S., BACHILLER, D., AGIUS, E., BELO, J.A., YAMAMOTO, A., HAINSKI-BROUSSEAU, A., BRIZUELA, B. et al. (1997). Patterning by genes expressed in spemann's organizer. Cold Spring Harb Symp Quant Bio/62: 169-75.

DJE, M.K., MAZABRAUD, A., VIEL, A., LE MAIRE, M., DENIS, H., CRAWFORD, E. and BROWN, D.D. (1990). Three genes under different developmental control encode elongation factor 1 -alpha in Xenopus laevis. Nucleic Acids Res 18: 3489-93.
FREIJE, J.M., BALBIN, M., PENDAS, A.M., SANCHEZ, L.M., PUENTE, X.S. and LOPEZ-OTIN, C. (2003). Matrix metalloproteinases and tumor progression. Adv Exp Med Bio/532: 91-107.

HAMMOUD, L., WALSH, L.A. and DAMJANOVSKI, S. (2006). Cloning and developmental characterization of Xenopus laevis membrane type-3 matrix metalloproteinase (mt3-mmp). Biochem Cell Bio/84: 167-77.

HERNANDEZ-BARRANTES, S., BERNARDO, M., TOTH, M. and FRIDMAN, R. (2002). Regulation of membrane type-matrix metalloproteinases. Semin Cancer Bio/12: 131-8.

HOIKKALA, S., PAAKKO, P., SOINI, Y., MAKITARO, R., KINNULA, V. and TURPEENNIEMI-HUJANEN, T. (2006). Tissue mmp-2/timp-2-complex are better prognostic factors than serum mmp-2, mmp-9 or timp-1 in stage i-iii lung carcinoma. Cancer Lett 236: 125-32.

HOLMBECK, K., BIANCO, P., CATERINA, J., YAMADA, S., KROMER, M., KUZNETSOV, S.A., MANKANI, M., ROBEY, P.G., POOLE, A.R., PIDOUX, I. et al. (1999). Mt1-mmp-deficient mice develop dwarfism, osteopenia, arthritis and connective tissue disease due to inadequate collagen turnover. Cel/99: 81-92.

JIANG, A. and PEI, D. (2003). Distinct roles of catalytic and pexin-like domains in membrane-type matrix metalloproteinase ( $\mathrm{mmp}$ )-mediated pro-mmp-2 activation and collagenolysis. J Biol Chem 278: 38765-71.

KANG, T., NAGASE, H. and PEI, D. (2002). Activation of membrane-type matrix metalloproteinase 3 zymogen by the proprotein convertase furin in the transgolgi network. Cancer Res 62: 675-81.

KANG, T., YI, J., YANG, W., WANG, X., JIANG, A. and PEI, D. (2000). Functional characterization of $\mathrm{mt} 3-\mathrm{mmp}$ in transfected mdck cells: Progelatinase a activation and tubulogenesis in 3-d collagen lattice. Faseb J14: 2559-68.

KLEIN, S.A., ANDERSON, G.L., KENNEDY, A.B. and BOND, S.J. (2002). The effects of a broad-spectrum matrix metalloproteinase inhibitor on characteristics of wound healing. J Invest Surg 15: 199-207.

MONTERO, J.A. and HEISENBERG, C.P. (2004). Gastrulation dynamics: Cells move into focus. Trends Cel/ Biol 14: 620-7.

NIEUWKOOP, P.D. and FABER, J. (1956). Normal table of Xenopus laevis (Daudin); a systematical and chronological survey of the development from the fertilized egg till the end of metamorphosis. Amsterdam, North-Holland Pub.

OSENKOWSKI, P., TOTH, M. and FRIDMAN, R. (2004). Processing, shedding and endocytosis of membrane type 1-matrix metalloproteinase (mt1-mmp). J Cell Physio/200: 2-10.

PICKARD, B. and DAMJANOVSKI, S. (2004). Overexpression of the tissue inhibitor of metalloproteinase-3 during Xenopus embryogenesis affects head and axial tissue formation. Cell Res 14: 389-99.

SASAI, Y., LU, B., PICCOLO, S. and DE ROBERTIS, E.M. (1996). Endoderm induction by the organizer-secreted factors chordin and noggin in Xenopus animal caps. Embo J15: 4547-55.

SASAI, Y., LU, B., STEINBEISSER, H., GEISSERT, D., GONT, L.K. and DE ROBERTIS, E.M. (1994). Xenopus chordin: A novel dorsalizing factor activated by organizer-specific homeobox genes. Cel/79: 779-90.

SHIMADA, T., NAKAMURA, H., OHUCHI, E., FUJII, Y., MURAKAMI, Y., SATO, H., SEIKI, M. and OKADA, Y. (1999). Characterization of a truncated recombinant form of human membrane type 3 matrix metalloproteinase. Eur J Biochem262: 907-14.

SOMERVILLE, R.P., OBLANDER, S.A. and APTE, S.S. (2003). Matrix metalloproteinases: Old dogs with new tricks. Genome Bio/4: 216.

SOMIARI, S.B., SHRIVER, C.D., HECKMAN, C., OLSEN, C., HU, H., JORDAN, R., ARCIERO, C., RUSSELL, S., GARGUILO, G., HOOKE, J. et al. (2006). Plasma concentration and activity of matrix metalloproteinase 2 and 9 in patients with breast disease, breast cancer and at risk of developing breast cancer. Cancer Lett 233: 98-107.

SOUNNI, N.E. and NOEL, A. (2005). Membrane type-matrix metalloproteinases and tumor progression. Biochimie 87: 329-42.

STAMENKOVIC, I. (2003). Extracellular matrix remodelling: The role of matrix metalloproteinases. J Patho/200: 448-64.

VANSAUN, M.N. and MATRISIAN, L.M. (2006). Matrix metalloproteinases and cellular motility in development and disease. Birth Defects Res C Embryo Today 78: 69-79.

WANG, P., NIE, J. and PEI, D. (2004a). The hemopexin domain of membrane-type 
matrix metalloproteinase-1 (mt1-mmp) is not required for its activation of prommp2 on cell surface but is essential for mt1-mmp-mediated invasion in three-dimensional type i collagen. J Biol Chem 279: 51148-55.

WANG, X., MA, D., KESKI-OJA, J. and PEI, D. (2004b). Co-recycling of mt1-mmp and $\mathrm{mt3}-\mathrm{mmp}$ through the trans-golgi network. Identification of dkv582 as a recycling signal. J Biol Chem 279: 9331-6.

WISEMAN, B.S., STERNLICHT, M.D., LUND, L.R., ALEXANDER, C.M., MOTT, J., BISSELL, M.J., SOLOWAY, P., ITOHARA, S. and WERB, Z. (2003). Sitespecific inductive and inhibitory activities of $\mathrm{mmp}-2$ and $\mathrm{mmp}-3$ orchestrate mammary gland branching morphogenesis. J Cel/ Bio/162: 1123-33.

WU, M. and GERHART, J. (1991). Raising Xenopus in the laboratory. Methods Cell Bio/36: 3-18.
ZHAO, H., BERNARDO, M.M., OSENKOWSKI, P., SOHAIL, A., PEI, D., NAGASE, H., KASHIWAGI, M., SOLOWAY, P.D., DECLERCK, Y.A. and FRIDMAN, R. (2004). Differential inhibition of membrane type $3(\mathrm{mt} 3)$-matrix metalloproteinase (mmp) and $\mathrm{mt} 1-\mathrm{mmp}$ by tissue inhibitor of metalloproteinase (timp)-2 and timp3 rgulates pro-mmp-2 activation. J Biol Chem 279: 8592-601.

Received: 29th November 2006 Reviewed by Referees: 5th January 2007 Modified by Authors and Accepted for Publication: 28th March 2007 Published Online: 4th June 2007

\section{Related, previously published Int. J. Dev. Biol. articles}

See our recent Special Issue on Invasion in Cancer \& Embryonic Development edited by Marc Mareel and Juan Aréchaga at: http://www.ijdb.ehu.es/web/contents.php?vol=48\&issue=5-6

Collective cell migration in morphogenesis and cancer

Peter Friedl, Yael Hegerfeldt and Miriam Tusch

Int. J. Dev. Biol. (2004) 48: 441-449

Matrix metalloproteinases in cancer: from new functions to improved inhibition strategies Alicia R. Folgueras, Alberto M. Pendás, Luis M. Sánchez and Carlos López-Otín

Int. J. Dev. Biol. (2004) 48: 411-424

Multiple stage-dependent roles for histone deacetylases during amphibian embryogenesis: implications for the involvement of extracellular matrix remodeling.

S Damjanovski, L M Sachs and Y B Shi

Int. J. Dev. Biol. (2000) 44: 769-776

Germinal tumor invasion and the role of the testicular stroma

Alejandro Díez-Torre, Unai Silván, Olivier De Wever, Erik Bruyneel, Marc Mareel and Juan Aréchaga Int. J. Dev. Biol. (2004) 48: 545-557

EGF and TGF alpha influence in vitro lung development by the induction of matrix-degrading metalloproteinases. G L Ganser, G P Stricklin and L M Matrisian

Int. J. Dev. Biol. (1991) 35: 453-461 


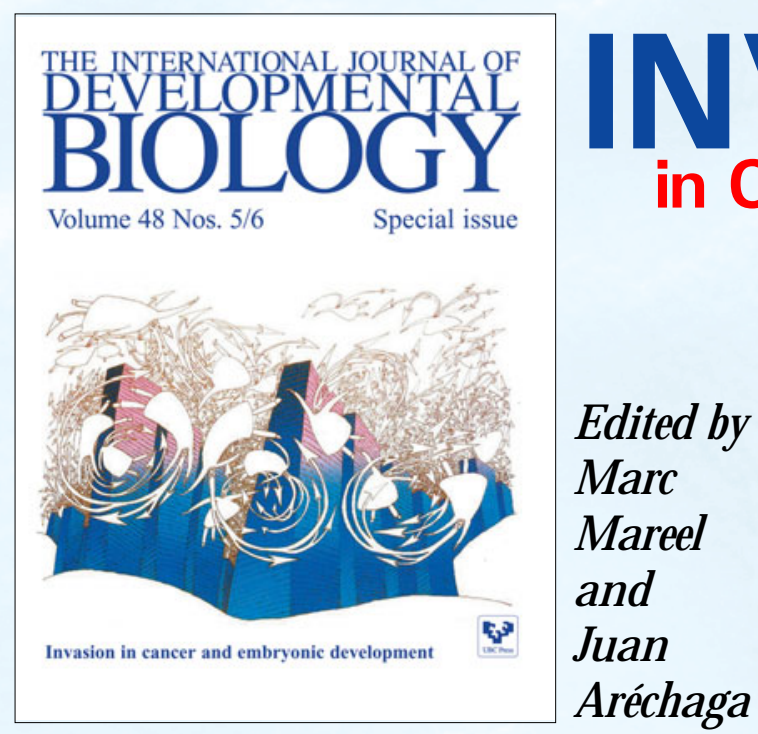

Vol. 48, Nos. 5/ 6

"I do not understand my images and anyone is free to understand them as he wishes. I have only tried to depict my own dreams..." J.M. Folon. This neo-surrealist painting entitled "Invasion" by Jean-Michel Folon (1934, Brussels, Belgium), with its swirling components against a stable background can be considered as a representation of avid cells breaking through the basement membrane to invade the adjacent stroma. With kind permission from J.-M. Folon (2004)

\section{Preface}

by $M$ arc $M$ areel and Juan A réchaga

\section{ONCOGENES, TUMOR SUPPRESSOR GENES \\ \& GENETIC REGULATION}

Molecular cell biology and cancer metastasis.

An interview with $\mathrm{G}$ arth Nicolson

by $\mathrm{M}$ arc $\mathrm{M}$ aree

Transcriptional regulation of cadherins

during development and carcinogenesis

by $\mathrm{H}$ éctor Peinado, Francisco Portillo and Amparo Cano

APC dosage effects in tumorigenesis and stem cell differentiation

by Claudia Gaspar and Riccardo Fodde

\section{ACTIVITIES OF INVASIVE CELLS}

Discovery and characterization of the cadherin family of cell adhesion molecules. An interview with Masatoshi Takeichi

by Douglas Sipp

Cadherin-mediated cell-cell adhesion and tissue

segregation in relation to malignancy

by Ramsey A. Foty and M alcolm S. Steinberg

Matrix metalloproteinases in cancer: from new functions to improved inhibition strategies

by Alicia R. Folgueras, Alberto M. Pendás, L uis M. Sánchez

and Carlos López-0 tín

Cytoskeletal mechanisms responsible for invasive migration of neoplastic cells

by Jury M. Vasiliev

Collective cell migration in morphogenesis and cancer

by Peter Friedl, Yael H egerfeldt and M iriam T usch
Invasive growth: a genetic program

by Alessandra Gentileand Paolo M. Comoglio

\section{INVASION SIGNALING PATHWAYS}

From here to there; a life based on migration.

An interview with Isaiah J. Fidler

by lan R. H art

$\mathbf{N}$-cadherin in the spotlight of cell-cell adhesion, differentiation, embryogenesis, invasion and signalling

by L ara D.M. Derycke and M arc E. Bracke

The Wnt connection to tumorigenesis

by Jürgen Behrens and Barbara L ustig

The chemokine network in cancer - much more than directing cell movement

by $\mathrm{H}$ agen Kulbe, $\mathrm{N}$ eil R. Levinson, Fran Balkwill and Julia L. Wilson

\section{PARTICIPATION OF THE HOST}

Brain tumour development and invasion.

An interview with O le Didrik Laerum

by Dieter $\mathrm{F}$. $\mathrm{H}$ ülser

The stroma reaction myofibroblast:

a key player in the control of tumor cell behavior

by A lexis Desmoulière, Christelle Guyot and Giulio Gabbiani

The countercurrent principle in invasion and metastasis of cancer cells. Recent insights on the roles of chemokines

by Ghislain Opdenakker and Jo Van Damme

\section{NORMAL EMBRYONIC INVADERS}

\& THEIR MALIGNANT COUNTERPARTS

The migration and differentiation of a chemist entangled in developmental and cancer biology. An interview with Jean-Paul Thiery

by Fred T. Bosman

Primordial germ cell migration

by Kathleen M olyneaux and Christopher Wylie

Germinal tumor invasion and the role of the testicular stroma

by Alejandro Díez-T orre, Unai Silván, Olivier DeWever,

Erik Bruyned, M arc M ared and Juan Aréchaga

\section{METHODOLOGY}

Tumor invasion and metastasis: getting more basic to come closer to the patient. An interview with Lance A. Liotta

by Vincent Castronovo

The "chemoinvasion assay" : a tool to study tumor and endothelial cell invasion of basement membranes

by Adriana Albini, Roberto Benelli, Douglas M. N oonan and Claudio Brigati

Novel technologies and recent advances in metastasis research

by Ivana Crnic and Gerhard Christofori

\section{THERAPEUTIC ASPECTS}

Parallels in invasion and angiogenesis provide pivotal points for therapeutic intervention by Suzanne A. Eccles

Pain control by ionizing radiation of bone metastasis

by LuCA.M .-L. Vakaet and T om B oterberg

\section{ORDER FORM}

I would like to order cop(y/ies) of the Int. J. Dev. Biol. Special Issue “Invasion in Cancer \& Embryonic Development” (Vol. 48, Nos. 5/6) at US\$ 90 or Euro $€ 70$ per copy (including post and packaging). Total to be charged: US\$ / Euro $€$ (please specify currency)

\section{ORDER BY}

$\checkmark$ Web: http://www.intjdevbiol.com

$\checkmark$ E-mail: ijdb@ehu.es (include the information indicated above)

$\checkmark$ FAX: +34-94-601-3266

$\checkmark$ POST: to the address shown to the right
The International Journal of Developmental Biology

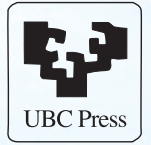

Editorial Office, Uni. of the Basque Country

Dept. Cell Biology and Histology

Faculty of Medicine, E-48940 Leioa

Vizcaya, SPAIN 